\title{
Factors Affecting the Central Corneal Thickness in Nepalese Population
}

\author{
Godar ST, ${ }^{1^{*}}$ Kaini KR, ${ }^{1}$ Khattri $\mathrm{JB}^{2}$
}

${ }^{1}$ Department of Ophthalmology, ${ }^{2}$ Department of Psychiatry, Manipal College of Medical Sciences, Pokhara, Nepal

\section{* Corresponding Author:}

Dr. Srijana Thapa Godar, MBBS, MS

Department of Ophthalmology

Manipal Teaching Hospital, Pokhara, Nepal

E mail: drsrijanathapa@yahoo.com

\section{Citation}

Godar ST, Kaini KR, Khattri JB. Factors affecting the central corneal thickness in nepalese population. Nepal Journal of Medical Sciences. 2012; 1(1): 7-10.

\begin{abstract}
Background: Intra Ocular Pressure (IOP) is an important parameter for the detection and monitoring of glaucoma. Central corneal thickness (CCT) can influence the IOP estimated with Goldmann tonometry. A thick cornea overestimates the IOP and thin underestimates it. So, decreased CCT may lead to underdiagnosis and undertreatment of glaucoma and increased CCT may lead to overdiagnosis and overtreatment of glaucoma. The aim of the study is to identify the factors affecting the CCT in Nepalese population.
\end{abstract}

Methods: A hospital based cross-sectional study which enrolled 152 subjects from period of January 2009 to May 2010. All subjects underwent ophthalmological examinations. CCT was measured with ultrasonic pachymeter and intraocular pressure was measured with Goldmann applanation tonometer.

Results: The mean $\pm \mathrm{SD}$ CCT of right and left eye was $538 \pm 32$ and $540 \pm 30 \mu \mathrm{m}$ respectively. CCT decreased with increasing age. Age and intra ocular pressure was significantly correlated with CCT. There was no significant correlation of gender and ethnicity with CCT.

Conclusion: CCT decreased with increasing age. CCT was significantly correlated with age and intra ocular pressure but not with gender and ethnicity.

Keywords: Nepalese; central corneal thickness; ultrasound pachymeter

\section{Background:}

Glaucoma is the leading cause of irreversible blindness in both developed and developing countries. It is a major eye problem leading to blindness in Nepal. According to National Blindness Survey (NBS) 1981, 1 it is the fourth major cause of blindness, the first three being cataract, iatrogenic sequelae of cataract and retinal diseases. A thick cornea causes a falsely high measurement if the thickness is due to increased collagen fibrils. ${ }^{2}$ Patient with normal tension glaucoma may have thinner cornea than normal resulting in under estimation of their intra ocular pressure and patients with thicker cornea can be misdiagnosed as ocular hypertension. ${ }^{2}$ Imbert- Fick law, ${ }^{2,3}$ which presupposes that for a normal thickness cornea $(520 \mu \mathrm{m}$ by optical pachymetry) anda $3.06 \mathrm{~mm}$ diameterplunger, the surface tension of tear film (which pulls on the plunger) will approximately offset the corneal rigidity (which pushes back on the plunger), allowing intra ocular pressure to be measured with reasonably accuracy. The effect of central corneal thickness (CCT) as a confounding factor affecting the accuracy of intra ocular pressure 
as measured by Goldmann applanation tonometry appears to be small and usually not clinically relevant. However, when CCT is markedly different from the normal, this factor should be taken into account. It is for this reason that during screening of glaucoma, CCT, should be considered in trying to decide which of these individuals require close observation or the initiation of therapy before definite damage occurs. Apart from the reasons why corneal thickness plays a role in glaucoma management, it has also been shown that lower CCT is significantly associated with worsened advanced glaucoma, worsened visual field, increased vertical and horizontal cup-disc ratios, and increased number of glaucoma medications. ${ }^{4}$

\section{Methods:}

This is a hospital based cross-sectional study conducted from January 2009 - May 2010 at Manipal Teaching Hospital, Pokhara. A total of 152 subjects having clear cornea were included in this study. A brief ocular history of participants was taken. Patients had undergone detailed ophthalmological examination. Visual acuity for distance and near was recorded with self - illuminating standard Snellen's letter chart or E - chart for illiterates at a distance of $6 \mathrm{~m}$ and $40 \mathrm{~cm}$ respectively.

Detailed slit - lamp evaluation was done for every subject under Haag streit 900 slit lamp. Evaluation of optic disc and posterior pole was done with the help of direct ophthalmoscope with Heine beta 200 using white light, using red free light. Also slit lamp evaluation with +90D was done. Intraocular pressure was recorded with Goldmann applanation tonometer. Gonioscopic examination was done. Central corneal thickness was measured with an ultrasonic pachymeter (Model no. Palm Scan TM AP 2000). After applying topical local anesthesia, the pachymeter tip was placed in the center of cornea in the mid-pupillary axis and 4 pachymetry readings were recorded and average value was obtained. All measurements were made between 8:30 am to $4: 30 \mathrm{pm}$.

\section{Results:}

In our study, age of study population ranges from 20 to 90 years, $45 \%$ were females and $55 \%$ were males. The maximum cases were Gurung followed by Newar, Magar, Brahmin and Chhetri. The mean \pm SD CCT of right and left eye was $538 \pm 32$ and $540 \pm 30 \mu \mathrm{m}$ respectively. The mean \pm SD intra ocular pressure of right and left eye was $12.39 \pm 2.34$ and $12.48 \pm 2.28 \mathrm{mmHg}$. Mean CCT was more in $<40$ years group, males and in Magar (Table1).

\section{Table 1: Mean CCT of different variables}

\begin{tabular}{llcc}
\hline \multirow{2}{*}{ Variables } & & \multicolumn{2}{c}{ CCT $(\mu \mathrm{m})$} \\
& & RE & LE \\
Age (Years) & $<40[\mathrm{n}=26(17 \%)]$ & $554.0 \pm 31.4^{*}$ & $554.9 \pm 29.7^{*}$ \\
& $>40[\mathrm{n}=126(83 \%)]$ & $535.5 \pm 32.4^{*}$ & $537.5 \pm 30.2^{*}$ \\
& Male & $540.5 \pm 31.4^{*}$ & $543.3 \pm 30.6^{*}$ \\
Gender & Female & $535.4 \pm 34.5^{*}$ & $537.3 \pm 30.7^{*}$ \\
& Brahmin & $541.7 \pm 30.1^{* *}$ & $547.8 \pm 30.1^{* *}$ \\
& Chhetri & $526.4 \pm 39.9^{* *}$ & $527.0 \pm 34.7^{* *}$ \\
& Gurung & $532.9 \pm 28.7^{* *}$ & $535.9 \pm 24.6^{* *}$ \\
Ethnicity & Magar & $547.9 \pm 32.5^{* *}$ & $547.73 \pm 31.2^{* *}$ \\
& Newar & $545.6 \pm 33.9^{* *}$ & $546.0 \pm 34.1^{* *}$ \\
& Others & $530.8 \pm 30.7^{* *}$ & $531.64 \pm 26.5^{* *}$ \\
\hline
\end{tabular}

${ }^{*}$ The difference in CCT is not significant ( $\mathrm{z}-$ test)

** The difference in CCT is not significant (ANOVA)

Table 2 showed age and intra ocular pressure was significantly correlated with CCT at 0.01 level ( 2 - tailed). There was no significant correlation of gender and ethnicity with CCT at 5\% level (2 - tailed).

Table 2: Correlation of different variables with CCT.

\begin{tabular}{lccc}
\hline \multicolumn{2}{c}{ Variables } & r & Sig. \\
\hline \multirow{2}{*}{ Age } & CCT (RE) & -0.386 & $0.000^{* *}$ \\
& CCT (LE) & -0.366 & $0.000^{* *}$ \\
Gender & CCT (RE) & 0.092 & 0.257 \\
& CCT (LE) & 0.111 & 0.175 \\
Ethnicity & CCT (RE) & 0.047 & 0.562 \\
& CCT (LE) & 0.000 & 0.996 \\
\hline$*$ Correlation is significant at the 0.01 level $(2-$ tailed)
\end{tabular}

The Karl Pearson's coefficient of correlation between CCT and IOP of right eye and left eye was 0.404 and 0.295 respectively. Both are significant at 0.01 levels $(2-$ tailed $)$ (Table 3).

\section{TABLE 3: Correlation of IOP and CCT}

\begin{tabular}{lcc}
\hline & CCT (RE) & CCT (LE) \\
\hline IOP (RE) & $0.404^{* *}$ & $0.295^{* *}$ \\
IOP $($ LE) & \\
\hline ** Correlation is significant at the 0.01 level $(2-$ tailed $)$
\end{tabular}


Figure 1 and 2 illustrate scatter diagram of CCT and IOP in study groups, showing a low positive relationship between CCT (RE), IOP (RE), CCT (LE) and IOP (LE).

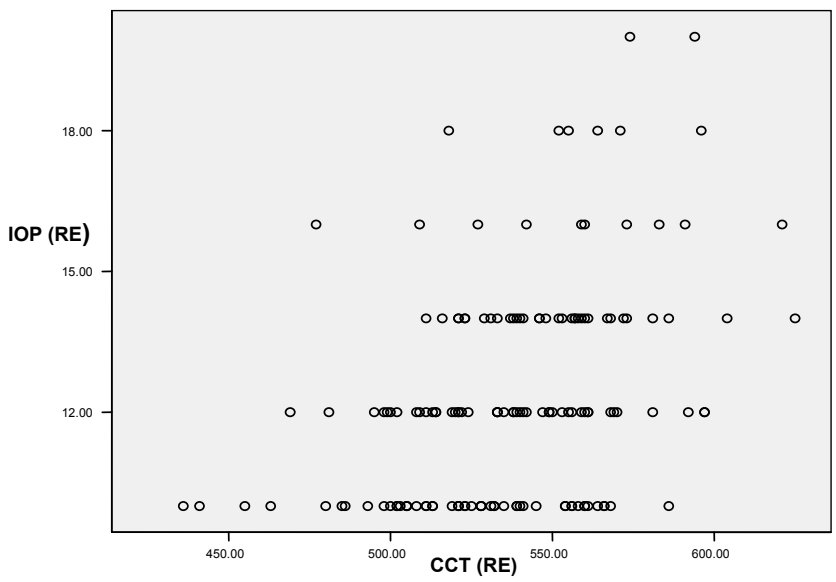

Figure 1: Scatter diagram of IOP against CCT (RE)

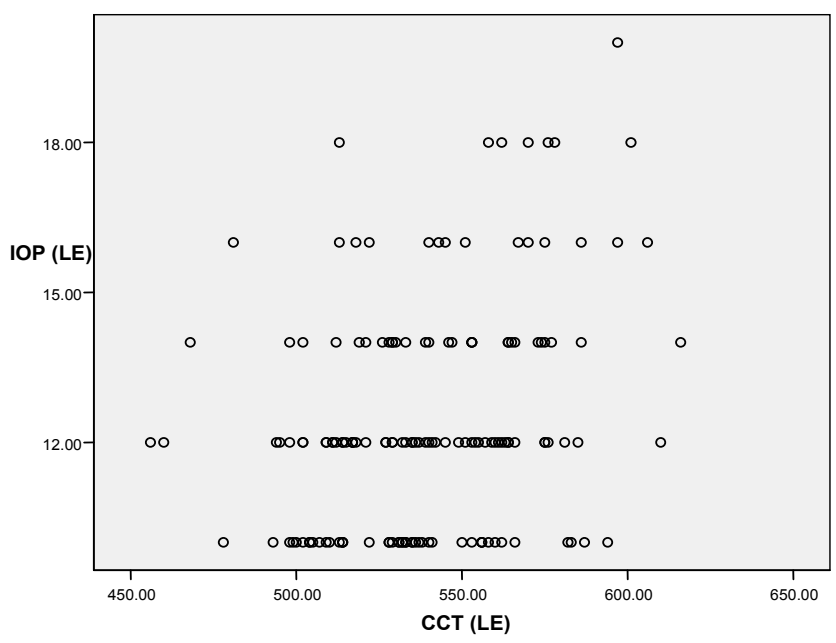

Figure 2: Scatter diagram of IOP against CCT (LE)

\section{DISCUSSION:}

Intra ocular pressure is an important risk factor that has a significant influence in the diagnosis and follow-up of glaucoma. The measurement of CCT aids in clinical assessment of glaucoma, ${ }^{5}$ increasing evidence suggests that CCT not only influences intra ocular pressure level but also predicts the risk of glaucomatous neuropathy. Goldmann and Schmidt had predicted in their original work that the intra ocular pressure reading theoretically could be affected by CCT. ${ }^{6}$ In our study mean CCT in right eye and in left eye was $538.2 \pm 32.8$ and $540.0 \pm 30.6 \mu \mathrm{m}$ respectively.

\section{Age Groups}

The maximum number of participants were found between $40-69$ years $(71 \%) .17 \%$ of them were less than 40 years of age and $83 \%$ were of more than 40 years (Table 1 ). This could easily be explained by the life expectancy of the Nepalese population. In our study mean CCT was found to be more in $<40$ years of age than that of $>40$ years (Table
1). Our study has similarity with the study done by Sora Hobn et al. which found thin CCT is in older individual. ${ }^{7,8 .}$ We noted negative significant relationship between age and CCT of (RE), CCT of (LE) at 0.01 level (2 - tailed) (Table 2). Stastistically significant negative correlation between age and CCT was shown by European Glaucoma Prevention study group and K Kawase et al. ${ }^{9}$ Similarly Elsa Aghaian et al also found a statistically significant inverse relationsip. ${ }^{10,11}$ Some studies reported CCT and age as contradictory. On the other hand there are some studies which have observed no significant association between those factors. ${ }^{12,13}$

\section{Gender distribution}

In our study, $45 \%$ were females and $55 \%$ males. This could be because of more attention being paid for the health of males. In Nepal, we have male dominating society and males are given much more importance in general. Our study is different from the study done by Sah RP et al. ${ }^{14}$ and Lingam Vijaya et al, ${ }^{15}$ who observed female participants more than male participants. Mean CCT was more in males in our study (Table 1). Here a positive insignificant correlation between gender and corneal thickness was noted (Table 2).

Our study has similarity with the study done by Mitsugu Shimmyo et al who observed CCT of males $(553.3 \mu \mathrm{m})$ to be thicker than of females $(548.0 \mu \mathrm{m})^{16}$ Similarly European Glaucoma Prevention study Group also noted greater CCT in males than in females. ${ }^{9}$ Danial HW 'The Singapore Malay Eye Study' observed that there was no difference in mean CCT between male $(540.7 \mu \mathrm{m}) \&$ female $(541.6 \mu \mathrm{m})^{5}$ while Rodrigo J Torres et al. observed CCT was greater in $\mathrm{AI} / \mathrm{AN}$ females than in $\mathrm{AI} / \mathrm{AN}$ males $(557.6,550.1 \mu \mathrm{m}$ respectively). ${ }^{17}$

\section{Ethnicity}

In our study Gurungs were 26\%, Newars 20\%, Magars $17 \%$, Brahmins $13 \%$, Chhetris $13 \%$ and others were $11 \%$. Mean CCT was more in Magars (Table 1). Ethnicity was not significantly correlated with CCT (Table 2).

\section{Central corneal thickness and intra ocular pressure}

Correlation between CCT and IOP of right eye was 0.404; similarly correlation between CCT and intra ocular pressure of left eye was 0.295 . Both are significant at 0.01 level (2-tailed) (Table 3). This study has similarity with studies by $\mathrm{K}$ Kawase et al, who showed that intra ocular pressure was significantly associated with CCT in adult Japanese population. ${ }^{18,19}$ There are few studies which have shown no correlation between CCT and intraocular pressure. M. Cristina leska et al. were not able to correlate baseline intra ocular pressure with CCT. ${ }^{19}$ Similarly in studies done in 
Black and ethnic Chinese, no positive correlation was seen between CCT and intra ocular pressure. ${ }^{20,21}$ Barbodos eye study also didn't find significant correlation between CCT and intra ocular pressure. ${ }^{22}$

\section{Conclusion:}

As reported in many previous studies we have also seen a negative significant correlation of age with CCT. We have noted a positive, significant correlation of CCT with IOP but not with gender or ethnicity.

\section{References:}

1. The Seva Foundation. The Epidemiology of Blindness in Nepal. Report of the Nepal Blindness Survey 1981, $160-4$.

2. Ehlers N, Bramsen T, Sperling S. Applanation Tonometry and Central Corneal Thickness. Acta Ophthalmol1975;53:34-43.

3. Imbert A. Theorie Ophthalmotonometries. Arch Ophthalmol (Paris)1888;5:358-63.

4. Herndon LW, Weizer JS, Stinnett SS. Central corneal thickness as a risk factor for the advanced glaucoma damage. Arch Ophthalmol 2004;122:17-21.

5. Su DHW, Wong TY, Wong WL, et al. Diabetes, Hyperglycemia, and Central corneal thickness. Ophthalmology 2008;115:964-8.

6. Goldmann H, Schmidt T. Uber Applanations tonometric. Ophthalmologie 1957;134:221-42.

7. Foster PJ, Baasanhu J, Alsbirk PH, et al. Central corneal thickness and intraocular pressure in a Mongolian population. Ophthalmology 1998;15:969-73.

8. Alsbirk PH. Corneal Thickness.I. Age variation, sex, difference and oculometric correlations. Acta Ophthalmol Scand 1978;56:95-104.

9. Europeon Glaucoma Prevention Study Group. Central corneal thickness in the Europeon Glaucoma Prevention Study. Ophthalmology 2007;114:454-9.

10. Brandt JD, Beiser JA, Kass MA, et al. central corneal thickness in the Ocular Hypertension Treatment Study (OHTS). Ophthalmology 2001;108:1779-88.

11. Hahn S, Azen S, Ying-Lai M, et al. Central corneal thickness in Latinos. Invest Ophthalmol Vis Sci 2003;44:1508-12.

12. Shimmyo M, Ross AJ, Moy A, et al. Intraocular pressure, Goldmann applanation tension, corneal thickness, and corneal curvature in Caucasians, Asians, Hispanics, and African Americans. Am J Ophthalmol 2003;136:603-13.
13. Wolfs RC, Klaver CC, Vingerling JR, et al. Distribution of central corneal thickness and its association with intraocular pressure: The Rotterdam Study. Am J Ophthalmol 1997;123:767-72.

14. Sah RP, Badhu BP, Pokhrel PK, et al. Prevalence of glaucoma in Sunsari district of Eastern Nepal. Kathmandu Univ Med J 2007;5:343-8.

15. Lingam V, George R, Baskaran M, et al. Prevalence of Primary open - angle glaucoma in an urban south Indian population and comparison with rural population: 'The Chennai Glaucoma Study'. Ophthalmology 2008;115:648-54.

16. Shimmyo M, Ross AJ, Moy A, et al. Intraocular pressure, Goldmann applanation tonometer, Corneal thickness, and Corneal curvature in Caucasions, Asians, Hispanics, and African Americans. Am J Ophthalmol 2003; 136: 603-13.

17. Torres RJ, Jones E, Edmunds B, et al. Central Corneal Thickness in Northwestern American Indians/ Alaskan Native and comparison with White and African - American Persons. Am J Ophthalmol 2008;146:747-51.

18. Kawase K, Tomidokaro A, Araie M, et al. Ocular and Systemic factors related to intra ocular pressure in Japanese adults: The Tajimi Study. Br J Ophthalmol 2008; 92: 1175-9.

19. Leske MC, Wu SY, Honkanen R, et al. Nine - year incidence of Open angle glaucoma in the Barbados Eye Studies. Ophthalmology 2007; 114: 1058-64.

20. Phillips LJ, Cakanac CJ, Eger MW, et al. Central corneal thickness and measured intraocular pressure: a clinical study. Optometry 2003; 74: 218-25.

21. Herndon LW, Weizer JS, Stinnett SS. Central corneal thickness as a risk factor for advance glaucoma damage. Arch Ophthalmol 2004;122:17-21.

22. Nemisure B, Wu SY, Hennis A, et al. Barbados Eye Study. Arch Ophthalmol 2003;121:240-4. 